\title{
Integrated Shale Gas Supply Chain Design and Water Management under Uncertainty
}

\author{
Omar J. Guerra ${ }^{a}$, , Andrés J. Calderón ${ }^{b}$, Lazaros G. Papageorgiou ${ }^{b}$, Gintaras \\ V. Reklaitis ${ }^{\mathrm{a}, *}$
}

a School of Chemical Engineering, Purdue University, West Lafayette IN 47907 USA.

b Department of Chemical Engineering, University College London, London WC1E 7JE, UK

$\S$ Now at National Renewable Energy Laboratory (NREL), Golden, C0 80401. E-mail address:

\section{OmarJose.GuerraFernandez@nrel.gov}

*Corresponding author. E-mail address: reklaiti@purdue.edu (G.V. Reklaitis).

\begin{abstract}
The development of shale gas resources is subject to technical challenges and markedly affected by volatile markets that can undermine the development of new projects. Consequently, stakeholders can greatly benefit from decision-making support tools that integrate the complexity of the system along with the uncertainties inherent to the problem. Accordingly, a general methodology is proposed in this work for the evaluation of integrated shale gas and water supply chains. First, key uncertain parameters are identified from a candidate pool via a global sensitivity analysis. Then, a two-stage stochastic model is developed considering only the key uncertain parameters in the problem. Moreover, the merits of modeling uncertainty and implementing the stochastic solution approach are evaluated using the expected value of perfect information and the value of the stochastic solution metrics. Furthermore, the conditional value-at-risk approach was implemented to evaluate different risk-aversion levels and the corresponding impacts on the shale gas development plan. The proposed methodology is illustrated through two real-world case
\end{abstract}


studies involving six and eighth potential well-pad locations and two options of well-pad layouts.

\section{Introduction}

The production of natural gas, and particularly shale gas, has gained increasing relevance in the energy sector. Indeed, under the International Energy Agency (IEA) base line scenario (New Policy Scenario), the natural gas demand will grow on average $\sim 1.5 \%$ per year from 2014 to 2040 reaching a share of roughly $24 \%$ of the global primary energy demand by $2040^{1}$. Moreover, shale gas is expected to account for around two-thirds of the natural gas production growth for the same time period ${ }^{1}$. Therefore, shale gas will continue to be a major player in the global energy market. However, the production of natural gas from sedimentary rocks with relatively low porosity and permeability entails important potential risks and challenges for sustainable operation. First and foremost, the development of shale gas could cause the degradation, contamination, and depletion of both surface and underground water sources 2,3 . Additionally, $\mathrm{CO}_{2}$ emissions represent a very important environmental concern associated with development of shale plays ${ }^{4-6}$. The water related issues are mostly due to the use of hydraulic fracturing, which is a water intensive artificial stimulation technique required to improve the connectivity of the fracture network in the shale formation. The water intensity in shale gas development is directly linked to the configuration and the productivity of the well-pad. Life cycle water consumption intensity of shale gas is estimated to be between 13 and 37 L/GJ (3.63-10.32 gallon/ million Btu), which is relatively high when compared with conventional natural gas (2.59-2.68 gallon/ million Btu) 7,8 . Moreover, the schedule of drilling and hydraulic fracturing operations is linked to the design and planning of gas and water transport and processing networks. Therefore, the integration of aspects such as the selection of the well-pad configuration, i.e. length of each horizontal well, number of hydraulic fractures per well, and number of wells per well-pad, the design and planning of the shale gas transportation and processing network, and the selection of the water management strategy are critical for any model-based system analysis aimed to evaluate the development of shale gas resources 9-11. Furthermore, the development of shale gas faces the uncertainties inherent to the oil and gas sector, i.e. shale play productivity, market conditions (gas demand and prices), freshwater availability, and 
wastewater composition ${ }^{12-16}$, which must be considered in the evaluation of any shale gas development.

Given these features of shale formations and the requirement of advanced production techniques, two of the topics that have attracted significant attention from the research community are the modeling and simulation of shale gas production systems 9,17-22. Moreover, data driven or simulation based tools have been developed for the economic assessment of natural gas production from shale gas plays 9,23,24, including considerations regarding the optimal well-pad layout 9,24 . Furthermore, supply chain optimization models have also been proposed for shale gas development $14,25-27$, for the corresponding water management problems $12,15,28,29$, and for the integrated shale gas development and water management problem ${ }^{9-11}$. Some of the aforementioned frameworks consider uncertainty in freshwater availability ${ }^{12}$, water demand for hydraulic fracturing as well as wastewater production ${ }^{15}$, gas production $13,14,27$, and gas prices ${ }^{14,27}$. Although significant progress has been achieved in the modeling, simulation, and optimization of shale gas development, further research efforts are needed towards the development of integrated supply chain models that deal with the uncertainties in a systematic way.

This study focuses on the development and implementation of an integrated two-stage stochastic optimization framework for the evaluation of shale gas resources. The stochastic framework is based on a deterministic optimization model developed previously by the authors 9,10 , wherein the selection of well-pad layouts, the design and planning of the shale gas transportation and processing network, and the selection of the water management strategy are addressed in an integrated manner. Furthermore, a global sensitivity analysis (GSA) ${ }^{30-32}$ is used in order to quantify and elucidate the effects of uncertain parameters on the economics of shale gas development.

\section{Materials and methods}

\section{Case Study Definition}


The strategic design and tactical planning of integrated shale gas and water supply chains (see Figure 1) involve decisions regarding the selection of freshwater sources for fracking operations, selection of well-pads layouts and locations, the design of liquid and gas transportation network, selection of location, technology, and capacity for wastewater treatment facilities, and the capacity and location for gas processing plants. In general, freshwater from a set of potential sources $f$ can be used to drill and perform fracturing operations on a set of potential well-pad locations $w$. Raw natural gas, produced at well-pad locations, is transported through a network of gas pipelines and compressors $c$ to the gas processing plants $p$. Three products are produced at the gas processing plants; methane, ethane, and $\mathrm{C}_{3+}$. Methane is delivered via gas pipelines to the national or regional pipeline network that delivers natural gas to different users, e.g. industrial and commercial sectors. Ethane is delivered through liquid pipelines to petrochemical facilities. However, heavier liquid hydrocarbons $\left(\mathrm{C}_{3^{+}}\right)$are assumed to be sold, at a certain plant-gate price, to customers at the gas plant locations. Besides raw shale gas, flowback and produced water (wastewater) are also generated at well-pad locations. Wastewater, i.e., flowback water, produced water or the corresponding blend, can be processed for reuse or recycle in water treatment facilities $h$. Alternatively, wastewater can be sent to disposal or injections sites $s$. In a previous work 9,10 , the authors developed and implemented a deterministic optimization framework for the optimal design and tactical planning of integrated shale gas and water supply chains. The deterministic framework considers different alternatives concerning freshwater sources and wastewater management strategies, well-pad layouts, and gas transportation and processing units. However, uncertainties were not considered in the problem formulation and therefore the solutions provided by such framework could be too risky or even impractical.

In this work, uncertainties in freshwater availability, water demand for hydraulic fracturing, gas production, wastewater production and quality, and gas spot prices (see Figure 1) are considered. A system of six potential well-pad locations was selected as a case study (see Figure 2). The well-pads are located in the Middle Magdalena Valley Basin (a prospective Colombian shale play). Additionally, 2 well-pad designs ("MaxNPV" and 
"MinWI") were evaluated 9. Layout "MaxNPV" is a configuration that maximizes the well-pad net present value (NPV), while design "MinWI" is a configuration that minimizes the wellpad water intensity. The corresponding shale gas production profiles can be found in ref. ${ }^{9}$. The potential gas and water transportation and processing network consists of 2 compressor stations ( 2 sizes), 2 gas processing plants ( 2 sizes), 2 freshwater sources, 2 water treatment plants ( 2 sizes), and 2 disposal sites. Three demand centers are considered, i.e. two centers for methane and one center for ethane. Moreover, gas composition was assumed to remain constant and a planning horizon of 10 years (represented in 40 quarters, i.e. $t_{1}, t_{2} \ldots t_{40}$ ) was used.

The superstructure for the integrated shale gas and water supply chain (see Figure 2) was designed using the software ArcGIS $10.2^{33}$ as follows: Shale gas from well-pads W1 and W4 can be transported to the compressor station 1, while shale gas from well-pads W2 and W3 can be sent to compressor station 2. Gas production from well-pad W6 can be transported to compressor stations 1 and/or 2, while shale gas from well-pad W5 is sent directly to gas processing plant 2 . Based on the geochemistry information of the shale play, wet-gas is produced from the site of the shale formation in which the 6 well-pads are located 9,10. Raw shale gas can be processed at the two gas plants, and then the final products, i.e. gas methane and liquid ethane, are delivered to the three demand centers. Three delivery points of the Colombian National pipeline network are considered as demand centers. The gas product methane from gas processing plant 1 and 2 can be sent to two injection points located in the southwest and southeast of the shale play, respectively. These two injection points are then connected to several natural gas power plants. The liquid product ethane can be delivered to an injection point located in the north of the shale play. This injection point is connected to a petrochemical facility. The prices of methane and ethane were based on data from the Colombian Mining and Energy Planning Unit-UPME (http://www1.upme.gov.co/). Three rivers provide freshwater for drilling and hydraulic fracturing operation in the well-pad locations. Water demand at well-pads W1, W2, and W4 
can be supplied from river III; river II is the water source for well-pad W3 while water requirements at well-pads W5 and W6 can be provided by river I. The wastewater from wellpad locations can be transported by truck to the two wastewater treatment plants. Additionally, the wastewater can be transported directly for deep injection from well-pad location to the injection well located at the north of the shale play. The treated water from the wastewater treatment facilities can be reused or recycled for drilling and hydraulic fracturing operations in new well-pads or discharged in rivers I and II. Trucking is the only water transportation mode considered, though additional transportation modes could be included if appropriate.

The potential transportation network for the integrated gas and water supply chain was based on a road network that connects the freshwater sources with the well-pad locations (demand points) and the well-pad locations with the wastewater treatment facility sites. In the gas transportation infrastructure design, three different pipeline capacities were used. Each of these capacities corresponds to a specific commercial diameter with the distances between each pair of connected nodes, e.g. the distance between a certain well-pad location and a certain compressor station given. Process simulations, carried out with Aspen Hysys ${ }^{\circledR}$, were used to estimate the commercial diameters, while the software ArcGIS $10.2^{33}$ was used to calculate the total distances between each pair of nodes of the pipeline network. This data, i.e., commercial diameters and distances, was used to determine the capital cost required for the installation of each pipeline section. Regarding compressor stations, capacities of 150 and 300 MMSCFD were considered for the case study. The corresponding capital cost was supplied by a local engineering and construction company in Colombia, under a confidentiality agreement. The software Aspen Hysys ${ }^{\circledR}$ was used to estimate the operational cost, including energy consumption, for each compressors station. Three capacities were considered for the two gas processing plants, i.e. 100, 200 and 350 MMSCFD. Simulations carried out with Aspen Hysys ${ }^{\circledR}$ and Aspen Capital Cost Estimator ${ }^{\circledR}$ combined with information from local engineering and construction companies in Colombia were used to estimate the corresponding capital and operating costs. 
Regarding the water management, the transportation costs for freshwater, wastewater, and treated water were estimated based on the road network distances between each pair of nodes of the corresponding supply chain. Freshwater availability at rivers I, II and III is estimated to be enough to drill and hydraulic fracture 14 wells during the rainy season, i.e. the third quarter of each year. For the first quarter of each year, which corresponds to the dry season, the available freshwater was projected to be $\sim 50 \%$ of the freshwater availability during the rainy season. Additionally, the freshwater available during the second and fourth quarters was estimated to be $\sim 75 \%$ of the corresponding availability during the rainy season. Moreover, the freshwater quality in terms of total dissolved solids (TDS) concentration for the rivers I, II and III was estimated to be 130, 150 and $140 \mathrm{mg} / \mathrm{l}$, respectively. In this study we considered spatial variations, i.e. with well-pad location, in the TDS concentration in the wastewater, which varies between 34,300 and $106,700 \mathrm{mg} / \mathrm{l}$. The capacities of wastewater treatment facilities were discretized at levels of 94,500, 220,500 and 441,000 gal/day. The wastewater treatment plant 1 uses primary treatment technology and can handle wastewater with up to $50,000 \mathrm{mg} / \mathrm{l}$ of TDS. The wastewater treatment plant 2 utilizes secondary treatment technology and can treat wastewater with up to $120,000 \mathrm{mg} / \mathrm{l}$ of TDS. This treatment facility reduces the TDS concentration to $100 \mathrm{mg} / \mathrm{l}$, while no reduction in TDS concentration can be achieved in plant 1 . The capital and operating costs, adjusted to the Colombian context, were provided by local engineering and construction companies under a confidential agreement. A limit of 40,000 and 200,000 gal/day in the discharge water flow rate was considered for rivers I and II. A limit of 336,000 gal/day was set for the capacity of the deep injection well, which has an operating cost of $\sim 0.75 \mathrm{USD} /$ gal.

\section{Deterministic optimization framework for integrated shale gas and water supply chain management.}

The main aspects and decision elements considered in the mathematical formulation of the deterministic planning framework for integrated shale gas and water supply chains, developed by the authors ${ }^{10}$, are summarized in Table $\mathbf{1}$. This planning framework was used to address a variety of case studies, including the analysis of the mathematical formulation of water quality constraints as well as the water-energy-economics nexus associated with 
the development of shale gas resources in Colombia 10,11,34. The reader is referred to the original publication 10 for more details regarding the mathematical formulation and implementation of the deterministic framework, e.g., detailed description of the model variables, constraints, and parameters.

\section{Uncertain Parameters and Global Sensitivity Analysis (GSA)}

As mentioned previously, in this study we consider six categories of uncertain parameters, i.e. freshwater availability, water demand for hydraulic fracturing, gas production, wastewater production flow rate, wastewater quality (TDS concentration), and gas spot prices, for the design and planning of the integrated shale gas and water supply chain. Data on the uncertainty in natural gas prices, low, medium, and high scenarios were obtained from ref. ${ }^{35}$. Additionally, variations of $+/-30 \%$ were considered for freshwater availability, water demand for hydraulic fracturing, and wastewater production flow rate. Similarly, variations of $+/-25 \%$ and $+/-10 \%$ were assigned to gas production profiles and TDS concentration in wastewater, respectively. With these uncertainty descriptions, a GSA 30-32 was implemented (See Figure 3) using the group sampling methodology ${ }^{31}$ for uncertain parameters that depends on time and/or location, i.e. freshwater availability, gas production, wastewater production flow rate, wastewater TDS concentration, and gas spot prices. The deterministic optimization framework developed by the authors 9,10 was used to evaluate the impact of the uncertainties on different output variables, including the NPV of the integrated shale gas and water supply chain.

The methodology for the global sensitivity analysis consists of the following steps: First, the set of uncertain parameters to be assessed is specified (candidate pool), e.g. six parameters in this case, and a probability distribution function (PDF) must be selected for each uncertain parameter. In this work a uniform distribution for all of the six uncertain parameters was chosen. The lower and upper bounds were based either on a percentage of 
variation, i.e. for freshwater availability, water demand for hydraulic fracturing, wastewater production flow rate, gas production profiles, and TDS concentration in wastewater, or low and high scenarios, i.e. for natural gas prices. Then, the Sobol's sequence ${ }^{36}$ sampling strategy, with 128 evaluation points, was implemented for the evaluation of first- $\left(S_{i}\right)$ and second $\left(S_{i, j}\right)$-order sensitivity indices, which can be calculated using Eq. (1) and Eq. (2), respectively. Indices $i, j$ indicate uncertain parameters. The expression $V\left(E\left(Z / P_{i}\right)\right)$ represents the variance of the expected value of the output variable $Z$, e.g., NPV associated with the development of the shale gas play, given parameter $P_{i}$. The total variance of the output variable $Z$ is represented by term $V(Z)$. The expression $V\left(E\left(Z / P_{i}, P_{j}\right)\right)$ represents the variance of the expected value of output variable $Z$ given $P_{i}$ and $P_{j}$. Finally, the total sensitivity indices $\left(S T_{i}\right)$, i.e. for each uncertain parameter, can be evaluated using Eq. (3). The GSA was implemented using the software SobolGSA ${ }^{37}$.

$$
\begin{gathered}
S_{i}=\frac{V\left(E\left(Z / P_{i}\right)\right)}{V(Z)} \forall i \\
S_{i, j}=\frac{V\left(E\left(Z / P_{i}, P_{j}\right)\right)-V\left(E\left(Z / P_{i}\right)\right)-V\left(E\left(Z / P_{j}\right)\right)}{V(Z)} \forall i, j \\
S T_{i}=S_{i}+\sum_{j} S_{i, j} \quad \forall i
\end{gathered}
$$

First order effects $\left(S_{i}\right)$ denote output variance imputable to each uncertain parameter without taking into consideration interactions with other parameters. Second order effects $\left(S_{i, j}\right)$ represent output variance attributable to binary interactions between uncertain parameters. Total effects $\left(S T_{i}\right)$ denote the aggregate contribution of each uncertain parameter to output variance, considering all possible interactions.

\section{Stochastic Optimization Framework: mathematical formulation}


Based on the outcome of the GSA, key uncertainties are identified. These key uncertainties are defined as the uncertain parameters with greatest impact on the design and planning of the integrated shale gas and water supply chain. Subsequently, a two-stage stochastic optimization model ${ }^{39,40}$ (See Figure 4) is formulated using the deterministic optimization model developed previously by the authors ${ }^{9,10}$ and the outcomes from the GSA. The decision variables associated with the design and planning of the integrated supply chain were divided into two sets, i.e. first- and second-stage decisions. Decisions regarding the selection of well-pad layouts and the schedule of drilling operations were chosen as firststage decisions, while decisions concerning gas and water transportation, processing, and delivery were selected as the second-stage decisions. The stochastic model was then formulated as a deterministic equivalent problem, i.e. a Mixed Integer Linear Programming (MILP) model, using the GAMS platform ${ }^{41}$. A summary of the main features of the stochastic model, illustrated in Figure 4, is presented in Table 2.

Stochastic optimization models can be computationally intensive, particularly if applications of practical scope are addressed. Instead of using the stochastic approaches, less rigorous strategies can be used to solve optimization problems that involve uncertain parameters. For instance, the uncertain parameters can be fixed at their expected values and then a deterministic optimization model can be applied. On the other hand, a given set of deterministic optimization problems can be solved and then heuristic rules can be used to combine the corresponding solutions 39,40 . However, these relatively simple solution approaches could be totally inaccurate or could lead to suboptimal solutions in many cases. Two metrics can be used to assess the value of modeling uncertainty and implementing the stochastic solution approach. The first, is the expected value of perfect information (EVPI) which measures "the maximum amount a decision maker would be ready to pay in return for complete (and accurate) information about the future" 39 . The second, the value of the stochastic solution (VSS), measures "the gain obtained from modeling random variables as such, avoiding to replace them with average values" ${ }^{\prime 2}$. The metric EVPI is defined as the difference between the NPV estimated using the wait-and-see solution approach $\left(Z^{\text {ws }}\right)^{39,40}$ and the optimal NPV associated with the stochastic formulation $\left(Z^{*}\right)$, see Figure 5. Moreover, 
the metric VSS is equal to the difference between the optimal NPV associated with the stochastic formulation $\left(Z^{*}\right)$ and the expected NPV of using the expected value solution $\left(Z^{d}\right)$, see Figure 5.

\section{Risk Management and Solution Strategy}

The classical two-stage formulation results in a solution which is expected-value based and thus does not provide any measure of risk. In practical applications of optimization under uncertainty, decision-makers need to quantify and control the level of risk associated with investment decisions. Therefore, different risk management approaches have been proposed in the literature ${ }^{43-45}$, including value-at-risk (VaR) and conditional-value-at-risk (CVaR) ${ }^{46-48}$. The VaR risk measure is a given user-defined percentile of loss distribution, while $\mathrm{CVaR}$ approximately or exactly, i.e., under certain conditions, equals the average of certain user-defined percentage of the worst-case loss scenarios ${ }^{44}$. The two approaches are discussed and compared in details in ref. ${ }^{44}$. The CVaR has a clear practical interpretation and is continuous with respect to the confidence level, however, it is more sensitive to estimation errors than VaR. Both approaches can be automatically implemented using the Extended Mathematical Programming (EMP) framework in GAMS 41.

To address the risk-aversion behavior of decision-makers, the conditional value-at-risk (CVaR) approach ${ }^{46,47}$ was implemented in order to illustrate the effects of the decisionmaker's aversion to risk on the investments associated with the development of shale gas resources (see Eq. (4)-(9) (based on Figure 4), parameter $\beta$ captures the risk-aversion of the decision-maker. If $\beta=0$, the expected value (profit) term is neglected and the problem formulation becomes the risk-averse model. If $\beta=1$, the risk term in the combined objective function is neglected and the problem formulation becomes equivalent to the risk-neutral model presented in Figure 4. The scalar $\alpha$ varies between 0 and 1. $\eta$ is an auxiliary variable and $V_{S}$ is a continuous positive variable that represents the maximum of 0 and $\eta-$ $\left(c^{T} x+q_{s}^{T} y_{s}\right)$. Red and blue colors are used to identify first stage and second stage decision variables in the formulation of the two-stage stochastic model, respectively. 


\section{CVaR Model formulation ${ }^{42}$ :}

$$
\text { Max } C V a R=\beta\left(c^{T} x+\sum_{s \in S} p_{s} q_{s}^{T} y_{s}\right)+(1-\beta)\left(\eta-\frac{1}{1-\alpha} \sum_{s \in S} p_{s} v_{s}\right)
$$

Subject to:

$$
\begin{gathered}
A x=b \\
W_{s} y_{s}+D_{s} x \leq h_{s} \quad \forall s \in S \\
\eta-\left(c^{T} x+q_{s}^{T} y_{s}\right) \leq v_{s} \quad \forall s \in S \\
v_{s} \geq 0 \quad \forall s \in S \\
x \in X, y_{s} \in Y, \forall s \in S
\end{gathered}
$$

The implementation of CVaR allows maximization of the expected NPV of the worst scenarios delimited by the quantile $(1-\alpha)$. In this case, a triangular probability distribution function was assumed for the uncertain parameters, i.e., with probabilities of $0.25,0.5$, and 0.25 for low, most likely, and high level of each parameter, respectively. Moreover, the effects of economies of scale in light of uncertainty was also investigated. For this purpose, the previous case study ( 6 well-pads case) was extended to accommodate two additional wellpads (8 well-pads case study ${ }^{34}$ ). However, due to the complexity of the resulting optimization model, the convergence of the model presented extensive running times and low-quality solutions. Therefore, a solution strategy that exploited some of the features of the optimization model was developed. In our model, the binary variable $W e l l D e s(d, w, t)$ was identified as the critical variable that affects the most the convergence of the model. Accordingly, a cluster-based strategy ${ }^{49}$ was designed which involves reducing the size of binary variable $W e l l D e s(d, w, t)$. This size reduction is carried out by fixing part of the variable to a specific value. The part of the variable that is fixed is selected based on predefined clusters. A cluster refers to a subset of well-pads $w$ that are grouped with some preselected criteria. The different solution strategy steps are described in Figure 6.

Initially, the number of well-pads composing one cluster should be set. In this case study, 3 and 4 well-pads per cluster were selected for the cases with 6 and 8 well-pads respectively. 
Thus, the solution strategy is based on a total of 2 clusters. The solution of the two clusters will be referred to as one "cycle" of the solution strategy. The number of well-pads per cluster is an important parameter that should be carefully selected since it establishes a trade-off between running times and quality of solutions. A high number of well-pads per cluster could increase the running times considerably, which in combination with the iterative nature of the strategy, will render the strategy ineffective. On the other hand, low number of well-pads per cluster can reduce running times but the optimal solutions could be substantially far from the optimal. Next, the number of global iterations, Gitr, and clusters iterations, itr, are set. It should be noted that itr is implicitly set by the total number of well-pads in the case study and the number of well-pads per cluster.

In this work, 10 global iterations and 2 clusters iterations (which make for one cycle) were used. The global iterations refer to the number of times the algorithm iterates over one cycle. This can be used to improve the solution obtained from the previous cycles. The next step requires finding an initial feasible solution that serves as a starting point for the iterative procedure, this solution is initially used to completely fix binary variable $\operatorname{WellDes}(d, w, t)$. Next, the global iteration, indexed by $i$, is initiated. A set containing the clusters used in each iteration, itr, must be built. For this, a selection criterion must be chosen in order to update the clusters in every global iteration. In this work, total production per well-pad, $\operatorname{Prod}(w)$, was used as the criteria for building the clusters. Parameter $\operatorname{Prod}(w)$ is sorted from largest to smallest value and split into subsets each containing the same number of well-pads as set at the beginning of the algorithm. These subsets are used to build set Cluster $(c, w)$. It is worth highlighting that this criterion gives priority during the optimization process to those well-pads with an estimated higher total production, since they are the first subset to be optimized. Other rules can be implemented such as total cost per well-pad, net income per well-pad, and different sorting such as smallest to largest value, or balanced values. it is up to the researcher to identify the best set of rules for each specific case. Once the clusters have been defined, the iterations within a cycle, indexed by $c$, initiate. Since part of the variable WellDes $(d, w, t)$ is already fixed, either by an initial feasible solution or a solution from a previous cycle, then part of the variable is freed as dictated by Cluster $(c, w)$. The resulting 
reduced model is subsequently optimized. The iterative procedure ends once the global iterations have been completed.

\section{Qualitative and quantitative analysis}

\section{Uncertainty quantification and global sensitivity analysis}

The qualitative results of the GSA are summarized in Figure 7. First order effects are represented by the color intensity of the bubbles, while total effects are represented by the sizes of the bubbles. The results indicate that uncertainty in gas production, gas prices, and TDS concentration in wastewater are the uncertainties with largest impact on the variability of the NPV of the integrated shale gas and water supply chain. Indeed, based on the quantitative results, roughly $23.2 \%, 11.1 \%$, and $10 \%$ of the variance of the NPV is due to the independent effect of the uncertainty in gas production, gas prices, and TDS concentration in wastewater, respectively. Therefore, about $44.3 \%$ of the variance in the NPV is due to the independent effects of these three parameters. Moreover, about $14.2 \%$, of the variance of the NPV is due to the binary interactions between gas production, gas prices, and TDS concentration in wastewater. In total, $58.5 \%$ of the variance of the NPV is associated with the individual and binary interactions of these parameters. By contrast, the individual effects for fresh water availability, waste water production, and water demand add up to $15.4 \%$. When total order effects are included, these parameters account for $20.5 \%$ of the NPV variance. Additionally, the independent effect of uncertainty associated with water demand for hydraulic fracturing, freshwater availability, and wastewater production flow rate on the variance of any output variables shown in Figure 7 was lower than $11.7 \%, 9.3 \%$, and 6.1\%, respectively. It is noteworthy that $34.4 \%$ of the variance of the water recycle share in the water supply mix (Water Recycle Mix) is due to binary interactions of the uncertainty in water demand with the other five parameters. In the case of freshwater availability, around $13.2 \%$ of variance in the share of recycled water is due to the binary interaction of uncertainty in the input parameter with the remaining five parameters. 
Based on the results from the GSA, the gas production, gas prices, and TDS concentration in wastewater will be considered as uncertain parameters in the formulation of the stochastic model, reducing the set of uncertain parameters in the stochastic formulation from 6 to 3 and therefore the computational burden is reduced while preserving a reasonable model accuracy.

\section{Stochastic optimization framework: Results and Discussion}

\section{Deterministic and Stochastic Solutions}

Both the deterministic model and the two-stage stochastic approach were evaluated in this study using the 6 well-pad case study. The model statistics for each problem formulation are presented in Table 3. The two-stage stochastic model incorporates 27 scenarios. These scenarios are associated with the combination of three random parameters, i.e. gas production, gas prices, and TDS concentration in wastewater, with low, medium, and high levels each. The optimization problems were solved using GAMS 25.1. The commercial solver CPLEX 12.6.1 was used to address the MILP optimization problems. All runs were performed on a server with Dual 2.4Ghz Intel Xeon E5620's with 4 Cores, 16 GB Ram running Debian Linux. An optimality gap of 1\% was set for all cases. As observed from Table 3, much more computational effort is required to solve the two-stage stochastic model compared with the deterministic problem formulation. The main reason for this is due to the relatively large number of binary variables associated with the stochastic model. It is well known, that generally the number of binary variables is a very critical factor in the computational times needed to solve MILP optimization models using the Branch \& Bound (B\&B) strategies, such as those implemented in CPLEX.

The results regarding the optimal NPV for different solution approaches are presented in Figure 8. Specifically, the NPV for the integrated shale gas and water supply 
chain was $\sim \$ 114.26$ million for the deterministic formulation (Expected value (EV) solution), in which expected values for the random parameters are used. The expected NPV associated with the use of the EV solution is just $\$ 2.97$ million. However, the NPV was $\sim$ \$3.14 million when the stochastic solution approach is used, i.e. when uncertainties in gas production, gas prices, and TDS concentration in wastewater are considered. Moreover, the NPV for the wait-and-see solution approach was $\sim \$ 153.59$ million. Therefore, the metrics EVPI and VSS could be estimated to be $\sim \$ 110.45$ and $\sim \$ 40.17$ million, respectively. We can conclude that, since EVPI is much higher than VSS, resolving the uncertainty is more valuable than implementing the stochastic solution approach. However, both the modeling of uncertainty as well as the implementation of the two-stage framework could bring significant benefits.

The selected well-pad layouts as well as the schedule of drilling and hydraulic fracturing operations for the deterministic and the two-stage stochastic approaches are summarized in Figure 9. In the deterministic solution approach all the well-pads locations are selected, while in the two-stage stochastic solution well-pad W4 was not chosen. It is noteworthy that well-pad W4 is the well-pad with the highest TDS concentration in the wastewater. In fact, the "MinWI" layout was selected for all of the well-pad locations that produce the wastewater with relatively high TDS concentrations. Even more important is the fact that the selected well-pad layout for each location is the same regardless of the solution approach. However, the schedule of drilling and hydraulic fracturing operation varies significantly depending on the treatment of uncertainty. For instance, well-pads W1 and W6 are drilled and fractured one and eight quarters earlier in the stochastic solution. Based on these results, the rescheduling of drilling and hydraulic fracturing operations together with avoiding the selection of well-pad locations in which wastewater with relatively high TDS concentration is produced seem to constitute an effective hedging strategy for the development of the integrated shale gas and water supply chain under uncertainty in gas production, gas prices, and TDS concentration in wastewater. 


\section{Risk Aversion and Economy of Scale}

In order to test the applicability of the cluster-based solution strategy, the two case studies mentioned previously in this section 2.1 and 2.5 , whose monolithic models were possible to solve, were used as validation based on the risk-neutral formulation. 10 global iterations as well as 3 well-pads per clusters ( 6 well-pads case study) and 4 well-pads per cluster ( 8 well-pads case study), i.e., 2 clusters per cycle, were used. The computational results are summarized in Table 4.

It can be seen from Table 4 that the cluster solution approach is able to provide better integer solutions than the monolithic approach in both cases. Although the computational cost associated with the cluster solution approach is much higher than that of the monolithic approach for the 6 well-pads case study, the cluster solution approach is more efficient than the monolithic approach for the 8 well-pads case study. For instance, the cluster solution approach finds a better integer solution, i.e., $1 \%$ increase in the objective function, than that provided by the monolithic approach, while reducing the computational time in $\sim 70 \%$. This result confirms the adequacy of the proposed solution to tackle larger and more complex optimization problems. Therefore, the solution strategy was implemented to solve the stochastic optimization problems for the 8 well-pads case study while considering the conditional value at risk (CVaR). Moreover, the effect of different risk-averse levels (1- $\beta$ ) on the economic performance of shale gas development was addressed through a parametric analysis. To this end, the parameter $\beta$ was varied systematically from 0 up to 1 with a step size of 0.25 . The parameter $\alpha$ was kept at $10 \%$. Moreover, the probability distribution functions associated with the uncertainty of input data were modified in order to investigate their impact on the economics of shale gas development. For instance, triangular distributions were used for all of the uncertain parameters, as follows: a probability of 0.25 
was set for the lower and upper levels, while a probability of 0.5 was assigned to the most likely value. The results are presented in Figure $\mathbf{1 0 .}$

The effect of varying the probability distribution functions can be determined by comparing the expected value obtained with $\beta=1(1-\beta=0)$ and the equivalent two-stage stochastic solution presented in Figure 8 for the 6 well-pads case study. For the new PDFs, the expected value increased from $\$ 43.14$ million to $\$ 55.25$ million. This situation is expected given the high value of the EVPI metric estimated previously using uniform PDFs for the uncertain parameters. Furthermore, the 6 well-pads case study is not profitable for risk-aversion levels equal or higher than $0.25(1-\beta \geq 0.25)$. Regarding the impact of $1-\beta$, as the decision makers are willing to minimize risk, the weighted objective function for the 8 well-pad case study decreased on average $\$ 78.7$ million for every increase of 0.25 in $1-\beta$. Accordingly, the objective function when a risk-averse level of $0.75(1-\beta)$ is considered is five times lower than that of the risk-neutral shale gas development. It is worth noticing that as more well-pads are introduced lower levels of risk become profitable in comparison with the case of 6 well-pad case study. Therefore, the economy of scales plays an important role in compensating for risk by making the supply chain more resilient to uncertainty. By comparing the optimal solutions for the 8 well-pad case study, risk-averse and risk-neutral developments, it is possible to understand the key decisions that allow decision makers to manage risk. Regarding the optimal drilling strategy (shown in Figure 11), the selection of the well-pad layouts remains unchanged; however, the schedule of drilling and fracturing operations undergoes some variations. For instance, when the original stochastic approach $(1-\beta=0)$ is compared with the CVaR risk management approach with $1-\beta=0.75$, wellpad W3 is drilled 11 quarters latter, while well-pad W8 is drilled 11 quarters earlier. Similar shifts are observed when different risk aversion levels are compared. It is noteworthy that in practice, decision-makers tend to consider both the expected NPV and the CVaR of the NPV at a given threshold. In this case the objective function could readily be modified, i.e. selecting a given value between 0 and 1 for parameter $1-\beta$, in order to consider risk using a user- 
defined value of the scalar $(\beta)$ weighting parameter. Besides the adaptation of investment decisions depending on the risk-aversion level, operational variables (second-stage decision variables) were also adjusted depending on the value of the scalar $1-\beta$. For instance, water re-use and recycling increase as $1-\beta$ increases from 0 to 0.75 . This shift compensates for uncertainty in the concentration of TDS in wastewater.

\section{Conclusions}

This work investigates the impact of uncertainty in key system parameters on the decisions associated with the development of integrated shale gas and water supply chains. While the ideas and formulations are general, they are made concrete by using a specific case study derived from the Colombian context.

First, based on a deterministic model, a global sensitivity analysis was used to identify the key uncertain parameters in the problem. Then, the stochastic model is formulated focused only on the key uncertain parameters, which are the most influential uncertainties in the optimization problem. For the 6 well-pads case study, the gas production, gas prices, and TDS concentration in wastewater were identified as the key uncertain parameters. The solution of the two-stage stochastic formualtion established that the TDS concentration in wastewater plays an important role in the hedging strategy for the development of shale gas resources under uncertainty. For instance, avoiding the selection of well-pad locations in which wastewater with relatively high TDS concentration is produced together with the rescheduling of drilling and hydraulic fracturing operations seems to be effective strategies to mitigate potential financial losses resulting from uncertainty in spot gas prices, gas production, and TDS concentration in wastewater. A cluster-based strategy was designed to tackle convergence issues due to the high complexity of the resulting models. The proposed strategy showed considerable improvement over the monolithic approach and made it possible to investigate larger case studies ( 8 well-pads case study). It was possible to quantify the cost of reducing risk in shale gas development while considering uncertainty. Moreover, results showed that economies of scale increase resiliency of the supply chain in light of uncertainty. These results confirm that the modeling of the uncertain parameters in 
the design and planning of integrated shale gas and water supply chains can be crucial. Furthermore, given the risks involved in shale gas development, it is important to include some measures of risk, such as $\mathrm{CVaR}$, in the decision-making process, since most decision makers do not act purely on expected net present value. While the case study results are limited to the specifics of the Colombian application, the strategies presented in this work can be extended to other problem domains, including other energy supply chain problems.

\section{Acknowledgments}

The authors would like to acknowledge the financial support from the Colombian Science Council (COLCIENCIAS) and the Colombia Purdue Institute (CPI).

\section{Literature Cited}

1. IEA. World Energy Outlook 2016. OECD Publishing; 2016. doi:10.1787/weo-2016-en.

2. Vidic RD, Brantley SL, Vandenbossche JM, Yoxtheimer D, Abad JD. Impact of Shale Gas Development on Regional Water Quality. Science. 2013;340(6134):12350091235009. doi:10.1126/science.1235009.

3. Olmstead SM, Muehlenbachs LA, Shih J, Chu Z, Krupnick AJ. Shale gas development impacts on surface water quality in Pennsylvania. Proc Natl Acad Sci U S A. 2013;110(13):4962-4967. doi:10.1073/pnas.1213871110.

4. Burnham A, Han J, Clark CE, Wang M, Dunn JB, Palou-Rivera I. Life-cycle greenhouse gas emissions of shale gas, natural gas, coal, and petroleum. Environ Sci Technol. 2012;46(2):619-627. doi:10.1021/es201942m.

5. Howarth RW, Santoro R, Ingraffea A. Methane and the greenhouse-gas footprint of natural gas from shale formations. Clim Change. 2011;106(4):679-690. doi:10.1007/s10584-011-0061-5.

6. Weber CL, Clavin C. Life cycle carbon footprint of shale gas: review of evidence and implications. Environ Sci Technol. 2012;46(11):5688-5695. doi:10.1021/es300375n.

7. Clark CE, Horner RM, Harto CB. Life cycle water consumption for shale gas and conventional natural gas. Environ Sci Technol. 2013;47(20):11829-11836. doi:10.1021/es4013855.

8. Guerra OJ, Reklaitis G V. Advances and challenges in water management within energy systems. Renew Sustain Energy Rev. 2018;82(February 2018):4009-4019. doi:10.1016/j.rser.2017.10.071.

9. Calderón AJ, Guerra OJ, Papageorgiou LG, Siirola JJ, Reklaitis G V. Preliminary Evaluation of Shale Gas Reservoirs: Appraisal of Different Well-Pad Designs via Performance Metrics. Ind Eng Chem Res. 2015;54(42):10334-10349. 
doi:10.1021/acs.iecr.5b01590.

10. Guerra OJ, Calderón AJ, Papageorgiou LG, Siirola JJ, Reklaitis G V. An optimization framework for the integration of water management and shale gas supply chain design. Comput Chem Eng. 2016;92:230-255. doi:10.1016/j.compchemeng.2016.03.025.

11. Guerra OJ, Calderón AJ, Papageorgiou LG, Reklaitis G V. Strategic Design and Tactical Planning for Energy Supply Chain Systems. In: Advances in Energy Systems Engineering. Vol 50. Springer International Publishing; 2017:47-74. doi:10.1007/978-3-319-42803-1_3.

12. Yang L, Grossmann IE, Manno J. Optimization models for shale gas water management. AIChE J. 2014;60(10):3490-3501. doi:10.1002/aic.14526.

13. Gao J, You F. Deciphering and handling uncertainty in shale gas supply chain design and optimization: Novel modeling framework and computationally efficient solution algorithm. AIChE J. 2015;61(11):3739-3755. doi:10.1002/aic.15032.

14. Tan SH, Barton PI. Optimal dynamic allocation of mobile plants to monetize associated or stranded natural gas, part II: Dealing with uncertainty. Energy. 2016;96:461-467. doi:10.1016/j.energy.2015.12.069.

15. Lira-Barragán LF, Ponce-Ortega JM, Guillén-Gosálbez G, El-Halwagi MM. Optimal Water Management under Uncertainty for Shale Gas Production. Ind Eng Chem Res. 2016;55(5):1322-1335. doi:10.1021/acs.iecr.5b02748.

16. Guerra OJ, Calderón AJ, Papageorgiou LG, Gintaras VR. Wastewater Quality Impact on Water Management in Shale Gas Supply Chain. In: Proceedings of the 26th European Symposium on Computer Aided Process Engineering - ESCAPE 26. Elsevier Masson SAS; 2016:1371-1376. doi:10.1016/B978-0-444-63428-3.50233-2.

17. Wu Y-S, Li J, Ding D, Wang C, Di Y. A Generalized Framework Model for the Simulation of Gas Production in Unconventional Gas Reservoirs. SPE J. 2014;19(05):845-857. doi:10.2118/163609-PA.

18. Heller R, Zoback M. Adsorption of methane and carbon dioxide on gas shale and pure mineral samples. J Unconv Oil Gas Resour. 2014;8:14-24. doi:10.1016/j.juogr.2014.06.001.

19. Patzek TW, Male F, Marder M. Gas production in the Barnett Shale obeys a simple scaling theory. Proc Natl Acad Sci U S A. 2013;110(49):19731-19736. doi:10.1073/pnas.1313380110.

20. Mohaghegh SD. Reservoir modeling of shale formations. J Nat Gas Sci Eng. 2013;12:22-33. doi:10.1016/j.jngse.2013.01.003.

21. Curtis JB. Fractured shale-gas systems. Am Assoc Pet Geol Bull. 2002;86(11):19211938. doi:10.1306/61EEDDBE-173E-11D7-8645000102C1865D.

22. Jarvie DM, Hill RJ, Ruble TE, Pollastro RM. Unconventional shale-gas systems: The Mississippian Barnett Shale of north-central Texas as one model for thermogenic shale-gas assessment. Am Assoc Pet Geol Bull. 2007;91(4):475-499. doi:10.1306/12190606068. 
23. Weijermars R. Economic appraisal of shale gas plays in Continental Europe. Appl Energy. 2013;106:100-115. doi:10.1016/j.apenergy.2013.01.025.

24. Wilson KC, Durlofsky LJ. Optimization of shale gas field development using direct search techniques and reduced-physics models. J Pet Sci Eng. 2013;108:304-315. doi:10.1016/j.petrol.2013.04.019.

25. Cafaro DC, Grossmann IE. Strategic planning, design, and development of the shale gas supply chain network. AIChE J. 2014;60(6):2122-2142. doi:10.1002/aic.14405.

26. Gao J, You F. Shale Gas Supply Chain Design and Operations toward Better Economic and Life Cycle Environmental Performance: MINLP Model and Global Optimization Algorithm. ACS Sustain Chem Eng. 2015;3(7):1282-1291. doi:10.1021/acssuschemeng.5b00122.

27. Drouven MG, Grossmann IE, Cafaro DC. Stochastic programming models for optimal shale well development and refracturing planning under uncertainty. AIChE J. 2017;00(504):3-194. doi:10.1002/aic.15804.

28. Gao J, You F. Optimal design and operations of supply chain networks for water management in shale gas production: MILFP model and algorithms for the waterenergy nexus. AIChE J. 2015;61(4):1184-1208. doi:10.1002/aic.14705.

29. Lira-Barragán LF, Ponce-Ortega JM, Serna-González M, El-Halwagi MM. Optimal reuse of flowback wastewater in hydraulic fracturing including seasonal and environmental constraints. AIChE J. 2016;62(5):1634-1645. doi:10.1002/aic.15167.

30. Sobol' I. Global sensitivity indices for nonlinear mathematical models and their Monte Carlo estimates. Math Comput Simul. 2001;55(1-3):271-280. doi:10.1016/S0378-4754(00)00270-6.

31. Saltelli A, Ratto M, Andres T, et al. Global Sensitivity Analysis. The Primer. Chichester, UK: John Wiley \& Sons, Ltd; 2007. doi:10.1002/9780470725184.

32. Kucherenko S, Rodriguez-Fernandez M, Pantelides C, Shah N. Monte Carlo evaluation of derivative-based global sensitivity measures. Reliab Eng Syst Saf. 2009;94(7):1135-1148. doi:10.1016/j.ress.2008.05.006.

33. ESRI. ArcGIS Desktop: Release 10.2.2. Redlands, CA: Environmental Systems Research Institute.; 2014.

34. Calderón AJ, Guerra OJ, Papageorgiou LG, Reklaitis G V. Disclosing water-energyeconomics nexus in shale gas development. Appl Energy. 2018;225:710-731. doi:10.1016/j.apenergy.2018.05.001.

35. Unidad de Planeación Minero Energética -UPME. Plan de Expansion de Referencia Generacion - Transmisión 2014-2028. Bogotá/Colombia; 2014.

36. Sobol' I. On the distribution of points in a cube and the approximate evaluation of integrals. USSR Comput Math Math Phys. 1967;7(4):86-112. doi:10.1016/00415553(67)90144-9.

37. Kucherenko S, Zaccheus O. SobolGSA Software. http://www.imperial.ac.uk/processsystems-engineering/research/free-software/sobolgsa-software/. Published 2017. 
38. Bilal N. Implementation of Sobol's Method of Global Sensitivity Analysis to a Compressor Simulation Model. 22nd Int Compress Eng Conf. 2014. http://docs.lib.purdue.edu/icec/2385.

39. Birge J, Louveaux F. Introduction to Stochastic Programming.; 2011. doi:10.1007/978-1-4614-0237-4.

40. $\quad$ King AJ, Wallace SW. Modeling With Stochastic Programming.; 2012. doi:10.1007/978-0-387-87817-1.

41. GAMS Development Corporation. General Algebraic Modeling System (GAMS). 2014.

42. Conejo AJ, Carrión M, Morales JM. Decision Making Under Uncertainty in Electricity Markets. Vol 153. Boston, MA: Springer US; 2010. doi:10.1007/978-1-4419-7421-1.

43. Eppen GD, Martin RK, Schrage L. A Scenario Approach to Capacity Planning. Oper Res. 1989;37(4):517-527. doi:10.1287/opre.37.4.517.

44. Sarykalin S, Serraino G, Uryasev S. Value-at-Risk vs. Conditional Value-at-Risk in Risk Management and Optimization. In: State-of-the-Art Decision-Making Tools in the Information-Intensive Age. INFORMS; 2008:270-294. doi:10.1287/educ.1080.0052.

45. Gatica G, Papageorgiou LG, Shah N. Capacity Planning Under Uncertainty for the Pharmaceutical Industry. Chem Eng Res Des. 2003;81(6):665-678. doi:10.1205/026387603322150516.

46. Rockafellar RT, Uryasev S. Optimization of conditional value-at-risk. J Risk. 2000;2(3):21-41. doi:10.21314/JOR.2000.038.

47. Rockafellar RT, Uryasev S. Conditional value-at-risk for general loss distributions. J Bank Financ. 2002;26(7):1443-1471. doi:10.1016/S0378-4266(02)00271-6.

48. Sedzro KSA, Kishore S, Lamadrid AJ, Zuluaga LF. Stochastic risk-sensitive market integration for renewable energy: Application to ocean wave power plants. Appl Energy. 2018;229(May):474-481. doi:10.1016/j.apenergy.2018.07.091.

49. Xu G, Bennett L, Papageorgiou LG, Tsoka S. Module detection in complex networks using integer optimisation. Algorithms Mol Biol. 2010;5(1):36. doi:10.1186/17487188-5-36.

\section{List of tables}

Table 1. Summary of the features of the deterministic planning framework for integrated shale gas

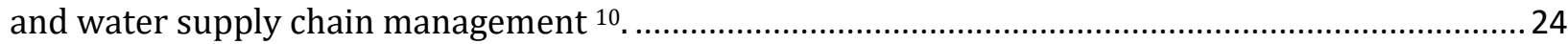

Table 2. Summary of the features of the stochastic optimization framework..................................26

Table 3. Model statistics and computational results for the 6 well-pad case study............................27 Table 4. Comparison between the proposed solution strategy and a monolithic approach for 6 and 8 well-pads and the risk-neutral formulation $(\beta=11-\beta=0)$. 
Table 1. Summary of the features of the deterministic planning framework for integrated shale gas and water supply chain management ${ }^{10}$.

\begin{tabular}{ll}
\hline Supply chain element & Description \\
\hline Objective function & The objective function is defined as the maximization of the net present \\
value (NPV) associated with the development of a shale gas reservoir \\
during a predefined planning horizon. The estimation of the NPV is \\
function of the income for final products sales, the operating costs, the \\
capital investments, and taxes and royalties incurred.
\end{tabular}

Revenue

Capital expenditures

Operating expenditures

Taxes and royalties

Freshwater supply Availability

Acquisition and transportation cost

\section{Well-pads}

Well-pad design and installation

Shale gas production

Shale gas composition

Water demand
The revenue refers to the earnings due to sales of final products, i.e., methane and ethane. In addition, depending of the characteristics of the reservoir, it is possible to produce condensates as part of the final products, which is this work are considered to be sold at a gate's price.

Capital expenditures refers to the investment in new infrastructure to transport and process raw gas into final products. In addition, investments are also required for installation of primary and secondary water treatment plants for recycle, re-use, and adequate disposal of wastewater.

The operational costs entail costs associated with the operation of wellpads, transportation of raw gas, operation of gas and water treatment plants, and transportation of final products to customers.

Taxation is estimated based on the income for products sales and depreciation of the assets. In this framework, taxes are defined only for positive cash flows. A different taxation scheme can be readily adapted to the framework. Moreover, royalties are payments to resource owners for the permission to explore and exploit the resources found in their lands.

Freshwater resources for drilling and fracturing of new production wells is limited according to the season of the year, the environmental flow, and downstream water demand.

Utilization of freshwater resources is subject to costs associated with acquisition and transportation from water sources to well-pads.

Binary variable, WellDes $(d, w, t)$, is used to account for decisions such as the design of a well-pad and the optimal time of installation. The binary variable equals 1 if drilling and hydraulic fracturing operations based on well-pad layout $d$ are performed at well-pad $w$ during time period $t$, the binary variable is 0 otherwise.

The gas production profile of a well-pad is determined by the design selected for such well-pad. The corresponding production profile is activated through binary variable $W$ ellDes $(d, w, t)$. The activation of the binary variable is limited by the number of drilling rigs available on site.

The composition of the raw gas is determined based on the characteristics of the formation of interest. The proposed framework can accommodate not only spatial but also temporal variability in composition.

The design selected for a well-pad defines the amount of water necessary for drilling and fracturing such well-pad. Fresh water, treated wastewater, or a combination of both, can be used to supply the water 
Water production

Water trans. cost

Capex and Opex

\section{Raw gas transportation} Pipeline capacity

Compressor stations

Capex and Opex

Wastewater treatment plants Plant capacity

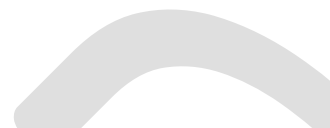

Material balance

\section{Gas treatment plants Plant capacity}

Material balance demand. Moreover, the concentration of TDS in water blends is constrained to meet technical specifications for reinjecting water into the formation.

Two streams, flowback water and produced water, are considered for calculating the total wastewater production. The flowback water refers to the fraction of injected water that returns to surface. The produced water refers to water originally in the formation and is produced along with raw gas. The wastewater can be treated for and re-used/recycled, or disposed of via for injection in depleted wells, or discharged into rivers.

The framework considers trucks as the transportation mode for taking wastewater from well-pads to disposal sites or water treatment plants.

The capital expenditures account for installation of new well-pads. In addition, the costs associated with operating each well-pad are also included and estimated based on the productivity of each well-pad.

The transportation of raw gas from well-pads to gas treatment facilities is limited by the installation of gas pipelines. The capacity of each pipelines and the period in which is installed are decisions subject to optimization.

Depending on the distance between production sites and gas processing facilities, installation of compressor stations may be required. Accordingly, the capacity and timing of the installation are subject to optimization.

The installed capacity of compressor stations and flow rates determine associated capital expenditures and operating costs, respectively.

The capacity and installation time of a wastewater treatment plant are decisions subject to optimization. Subsequently, these decisions define the amount of wastewater that can be processed and reutilized in future fracturing operations.

In order to meet TDS specifications and reduce treatment intensity, the framework accounts for blending of different wastewater qualities. A constrain is imposed to ensure that the selected technology of the treatment facility is adequate for treating the input stream.

Similar to wastewater transportation, treated water is transported to new drilling sites via trucking. The associated costs are included in the framework as part of operational costs.

Capital expenditures account for installation of water treatment plants. Operating costs are determined based on the transportation of treated water via trucks from water treatment facilities to new drilling sites.

Decisions regarding capacity and installation time of gas treatment plants are subject to optimization. These decisions determine the amount of raw gas that can be processed and sold to customers.

The efficiency in the separation of the different gas fractions is taken into account to estimate the production of final products. 
Sales

Capex and Opex

\section{Products transportation} Pipeline capacity

Capex

Demand supply

Disposal

Wastewater disposal

Opex
After the separation process, the fraction of condensates, C3+ hydrocarbons, are sold at the gas plant gate, whereas treated gas is sent to final customers.

Capital expenditures are estimated based on the installed capacity selected for a gas processing plant. Operating costs are estimated based on input raw gas flow rates.

Final products, Methane and Ethane, are delivered to customers by pipelines, whose capacity is subject to optimization.

The capacity selected for the installation of pipelines determines the associated capital expenditures.

Since the framework seeks for the maximization of profit, the supply of final products is constraint by the demand of customers included in the case study.

Two alternatives are considered in the framework for disposal of wastewater: 1) discharge into rivers or 2) injection in depleted wells (deep-injection).

Some disposal methods may have associated operational costs, i.e., deep-injection.

Table 2. Summary of the features of the stochastic optimization framework.

\begin{tabular}{ll}
\hline Model component & Description \\
\hline Objective function & $\begin{array}{l}\text { The expected net present value (NPV) associated with the development } \\
\text { of the integrated water and shale gas supply chain was selected as the } \\
\text { objective function to be maximized. The objective function has a } \\
\text { deterministic term that depends on the first stage decisions and a } \\
\text { stochastic term defined as the expectation of the second-stage objective. } \\
\text { The deterministic term is defined as the NPV of capital investments } \\
\text { associated with strategic decisions. The stochastic term is the NPV } \\
\text { related to tactical and operational decisions. }\end{array}$ \\
$\begin{array}{l}\text { First stage decisions (here and } \\
\text { now decisions) } \\
\text { First stage variables }\end{array}$ & $\begin{array}{l}\text { The first stage decisions are defined as the strategic decisions involved } \\
\text { in the development of the integrated supply chain. These decisions are } \\
\text { associated with the design of the well-pads and the scheduling of drilling } \\
\text { and hydraulic fracturing operations. }\end{array}$ \\
$\begin{array}{l}\text { First stage constraints } \\
\text { Second stage decisions (wait- } \\
\text { and-see decisions) } \\
\text { Second stage variables }\end{array}$ & $\begin{array}{l}\text { The first stage constraints are associated with the selection of the well- } \\
\text { pad layout for each location and the maximum number of wells that can } \\
\text { be drilled during each time period. }\end{array}$ \\
$\begin{array}{l}\text { The second stage decisions are related to the tactical and operational } \\
\text { decisions. These decisions include the selection of freshwater sources } \\
\text { for drilling and fracturing operations, the design and operation of water } \\
\text { and shale gas transportation and processing facilities, and the design of } \\
\text { transportation facilities for final products. }\end{array}$
\end{tabular}



constraints, including availability of freshwater, transportation and processing capacity constraints for water and shale gas, constraints for TDS concentration in drilling/fracturing operations and wastewater treatment plants, and material balances for water, shale gas and final products.

Table 3. Model statistics and computational results for the 6 well-pad case study.

\begin{tabular}{lcc}
\hline & Deterministic & Stochastic (SP) \\
\cline { 2 - 3 } Total number of variables & 7,779 & 197,375 \\
Continuous variables & 5,201 & 133,157 \\
Binary variables & 2,578 & 64,200 \\
Total number of constraints & 6,661 & 173,181 \\
Non zero constraint matrix elements & 87,171 & $2,175,617$ \\
CPU time & $12.5 \mathrm{~s}$ & $542 \mathrm{~s}$ \\
\hline
\end{tabular}

Table 4. Comparison between the proposed solution strategy and a monolithic approach for 6 and 8 well-pads and the risk-neutral formulation $(\beta=1(1-\beta=0))$.

\begin{tabular}{lccccc}
\hline \multirow{2}{*}{ Case study } & \multicolumn{3}{c}{ Monolithic model } & \multicolumn{2}{c}{ Cluster solution } \\
\cline { 2 - 6 } & $\begin{array}{c}\text { Integer solution } \\
\text { (\$ Million) }\end{array}$ & $\begin{array}{c}\text { Upper Bound } \\
(\$ \text { Million })\end{array}$ & $\begin{array}{c}\text { CPU time } \\
(\mathrm{h})\end{array}$ & $\begin{array}{c}\text { Solution } \\
(\$ \text { Million })\end{array}$ & $\begin{array}{c}\text { CPU time } \\
(\mathrm{h})\end{array}$ \\
\cline { 2 - 6 } 6 well-pads & 55.24 & 55.28 & 0.13 & 55.25 & 7.4 \\
8 well-pads & 289.35 & 313.05 & 135.7 & 292.25 & 41.0 \\
\hline
\end{tabular}




\section{List of figures}

Figure 1. Generic integrated shale gas and water supply chain (Reproduced from ref. 9,10). The uncertain parameters are listed in the red boxes.

Figure 2. Potential shale gas supply chain (Left-hand side) and potential water supply chain (Right-

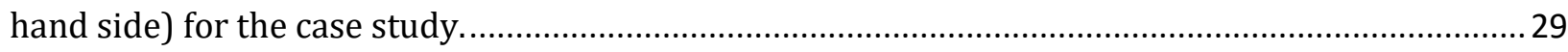

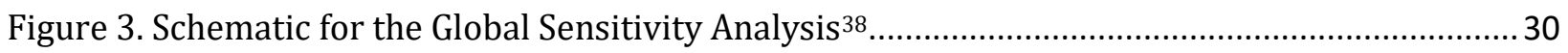

Figure 4. Two-stage stochastic optimization framework. A 10 year planning horizon (represented in

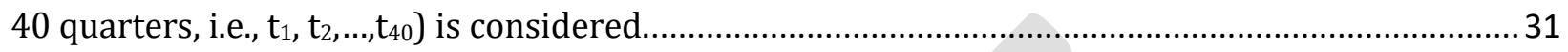

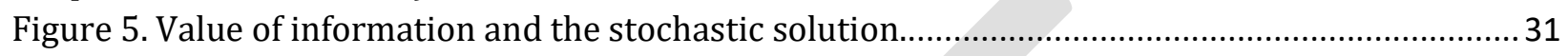

Figure 6. Cluster-based solution strategy .................................................................................. 33

Figure 7. Global sensitivity analysis for the design and planning of integrated shale gas and water

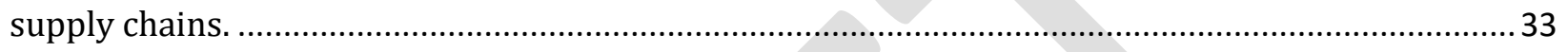

Figure 8. Optimal solutions for the 6 well-pad case study .......................................................... 33

Figure 9. Deterministic versus stochastic solutions for the 6 well-pad case study. ........................... 34

Figure 10. Effect of different risk aversion levels $(1-\boldsymbol{\beta})$ on the economics of shale gas development. Integer solution and upper bound for the monolithic solution approach are reported for 48 hours of CPU time. The CPU time for the cluster solution approach varies between 40.9 and 43.4 hours for the 8 well-pads case study, depending on the value of $\mathbf{1}-\boldsymbol{\beta}$.

Figure 11. Optimal drilling strategy for case study with 8 well-pads and different levels of risk aversion $(1-\beta)$. 36 


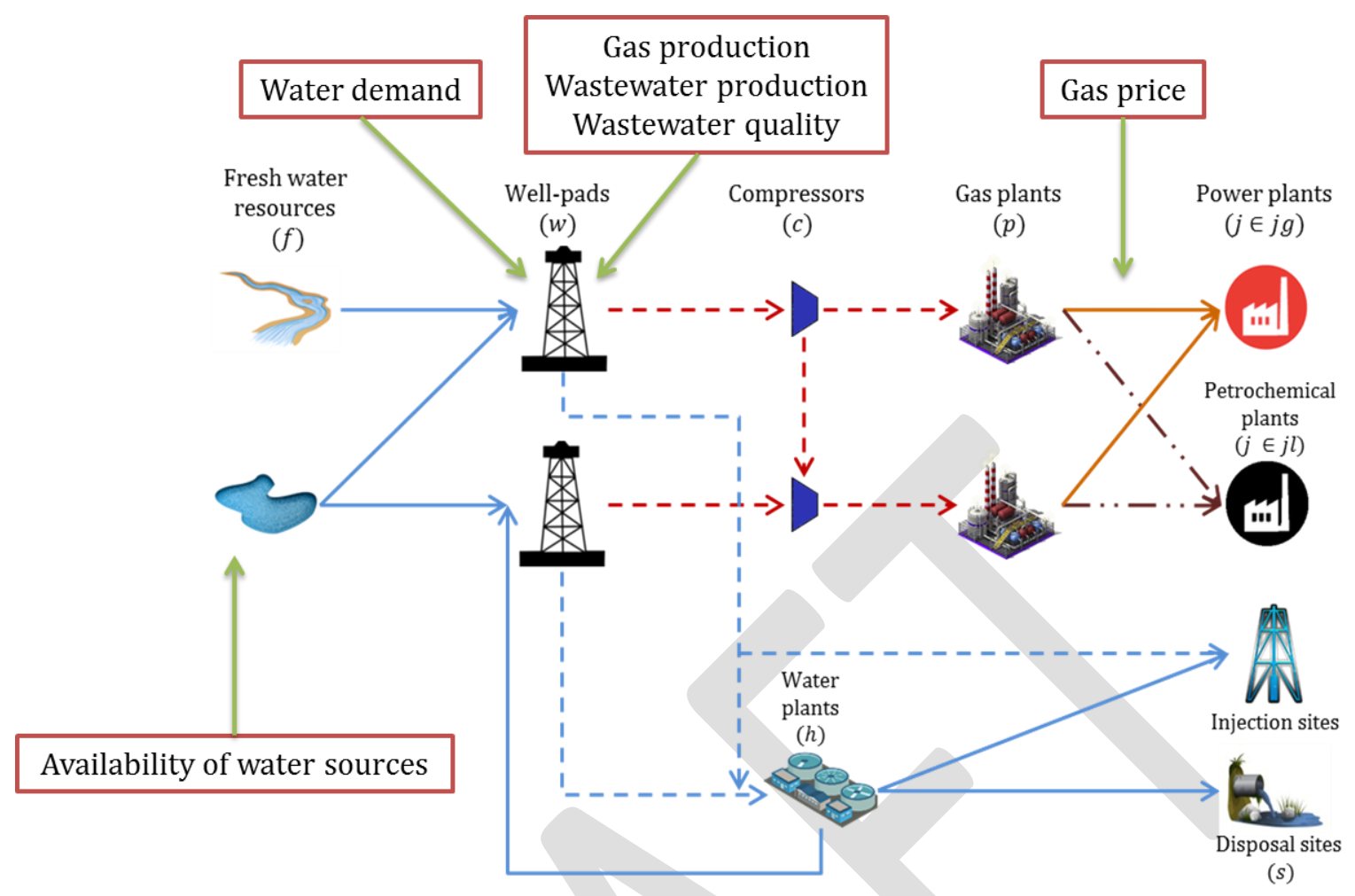

Figure 1. Generic integrated shale gas and water supply chain (Reproduced from ref. 9,10). The uncertain parameters are listed in the red boxes.
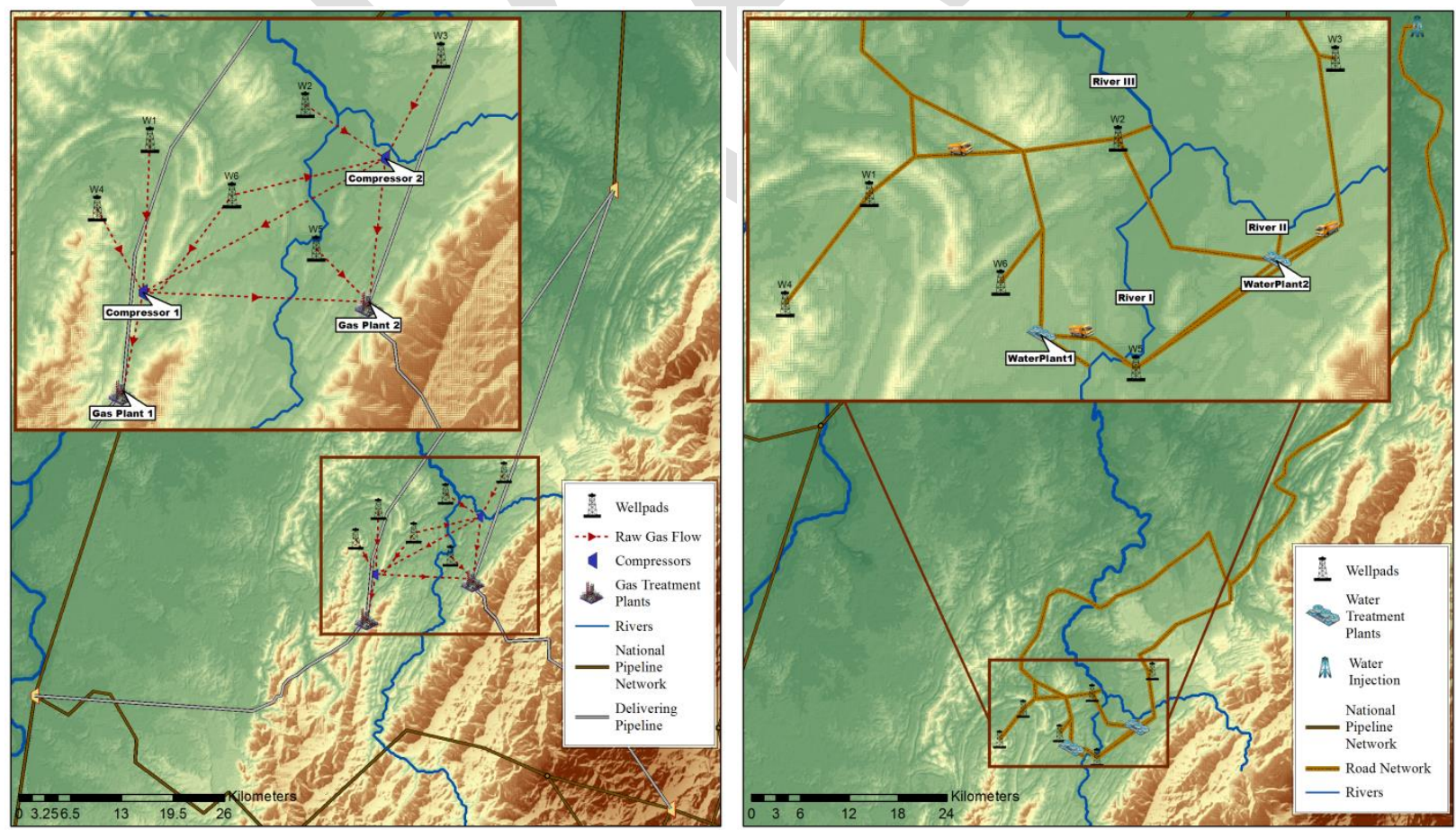

Figure 2. Potential shale gas supply chain (Left-hand side) and potential water supply chain (Right-hand side) for the case study. 


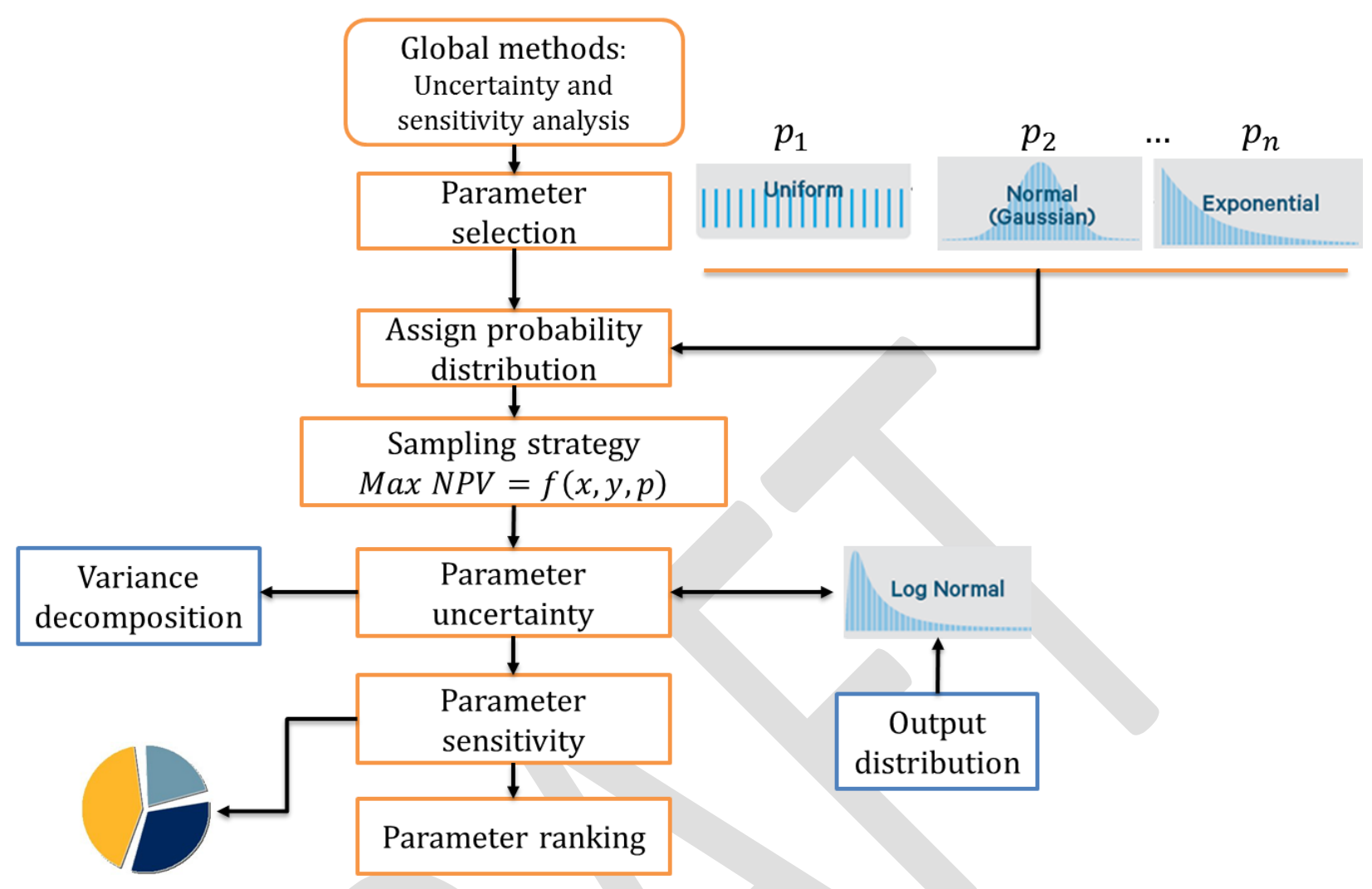

Figure 3. Schematic for the Global Sensitivity Analysis ${ }^{38}$ 


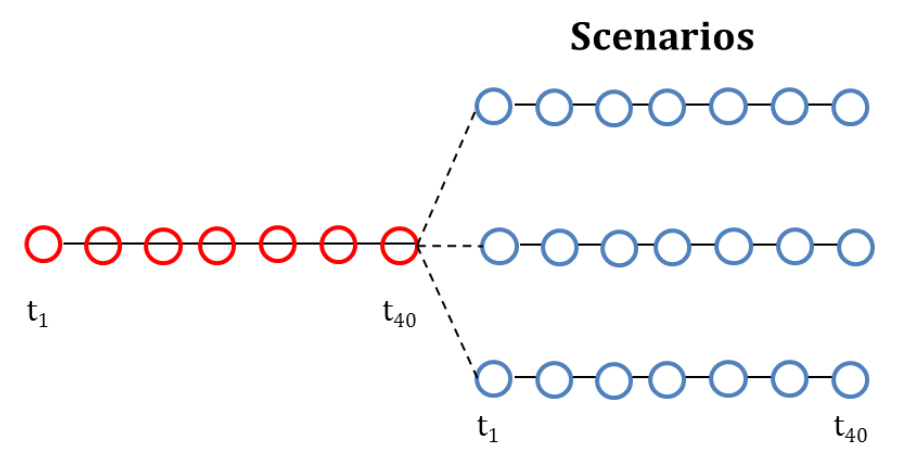

Two-stage stochastic formulation

(Deterministic equivalent problem-MILP)

$$
\operatorname{Max} z=c^{T} x+\sum_{S \in S} p_{s} q_{s}^{T} y_{S}
$$

s.t.

$$
\begin{aligned}
A x & =b \\
W_{s} y_{S}+D_{s} x & \leq h_{s} \quad \forall s \in S
\end{aligned}
$$

First stage decisions (Drilling/frac. decisions)
Second stage decisions (gas \& water trans./proc. decisions)

\section{Deterministic model in GAMS}

(Guerra 0J, Calderón AJ, Papageorgiou LG, Siirola JJ, Reklaitis G V. Comput Chem Eng 2016; 92:230-255.)

$$
\begin{gathered}
x \in X \\
y_{S} \in Y
\end{gathered}
$$

\section{EMP* information}

(Uncertain parameters)

\section{* EMP= Extended Mathematical Programming}

Figure 4. Two-stage stochastic optimization framework. A 10 year planning horizon (represented in 40 quarters, i.e., $\mathrm{t}_{1}, \mathrm{t}_{2}, \ldots, \mathrm{t}_{40}$ ) is considered.

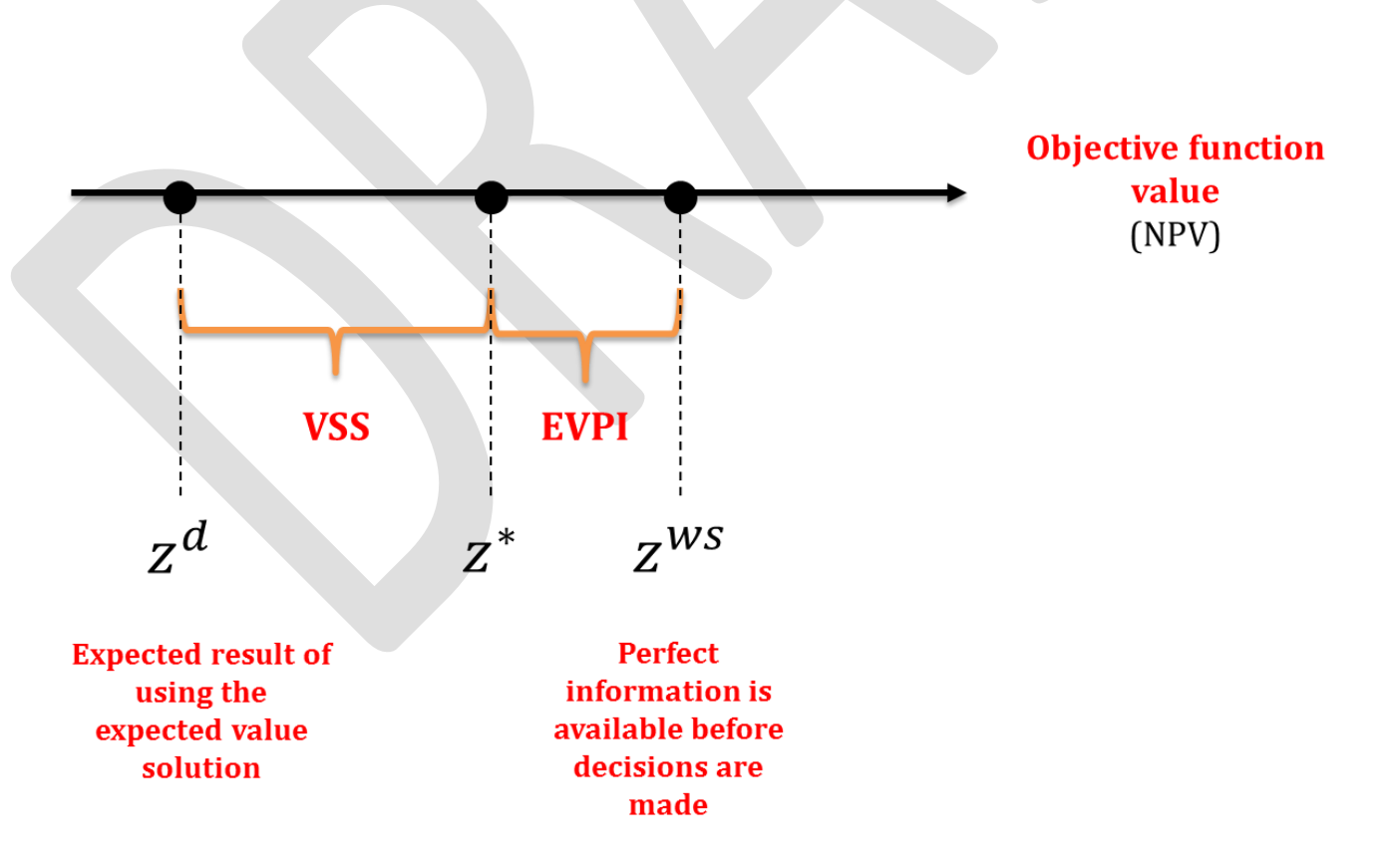

Figure 5. Value of information and the stochastic solution. 


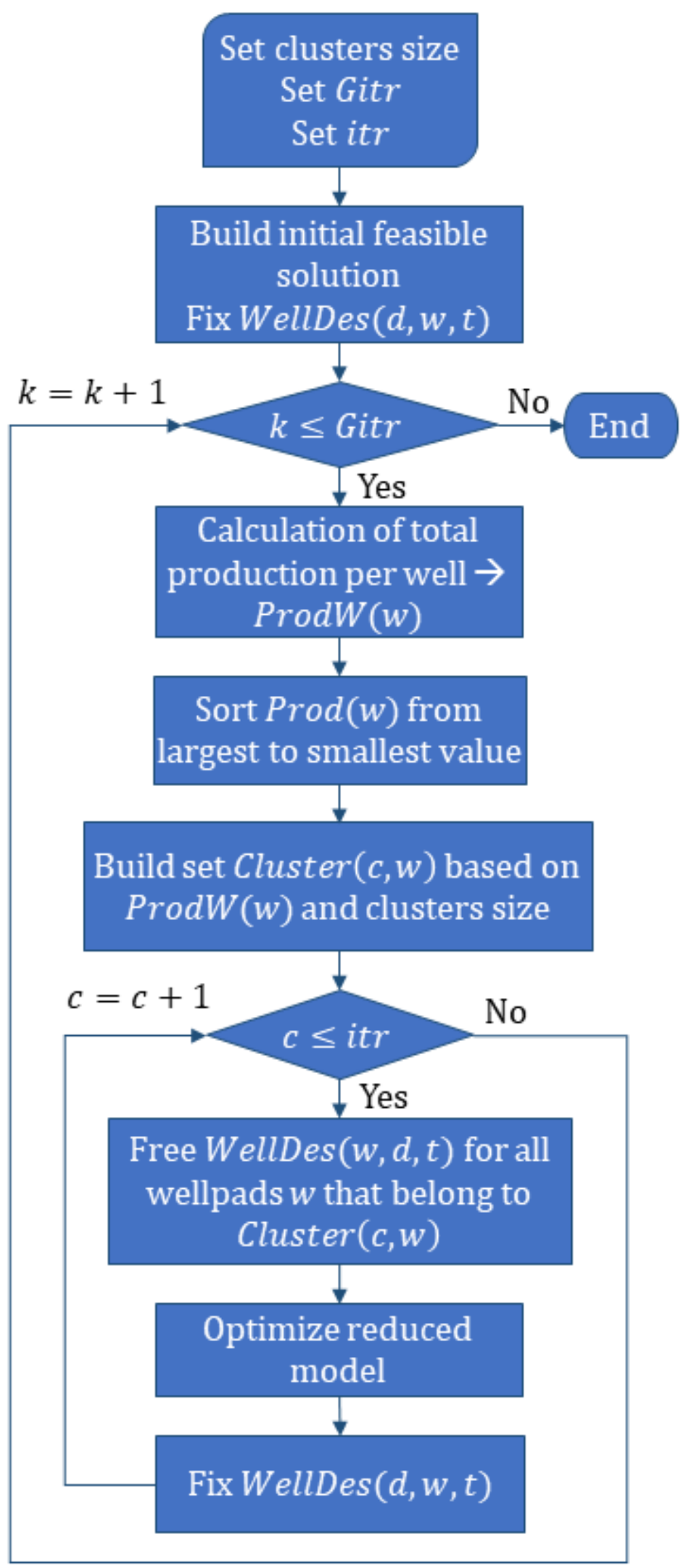


Figure 6. Cluster-based solution strategy.

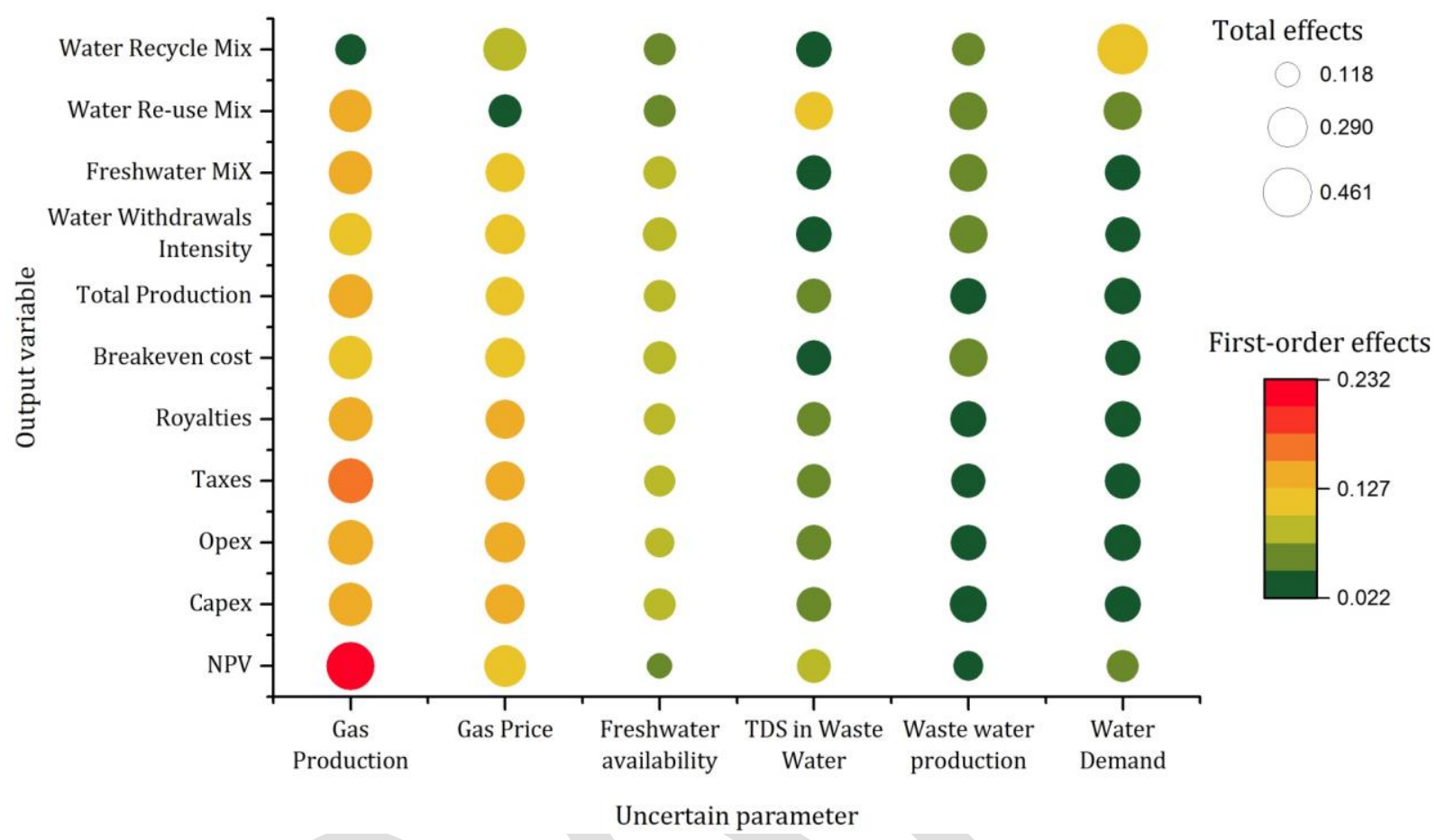

Figure 7. Global sensitivity analysis for the design and planning of integrated shale gas and water supply chains.

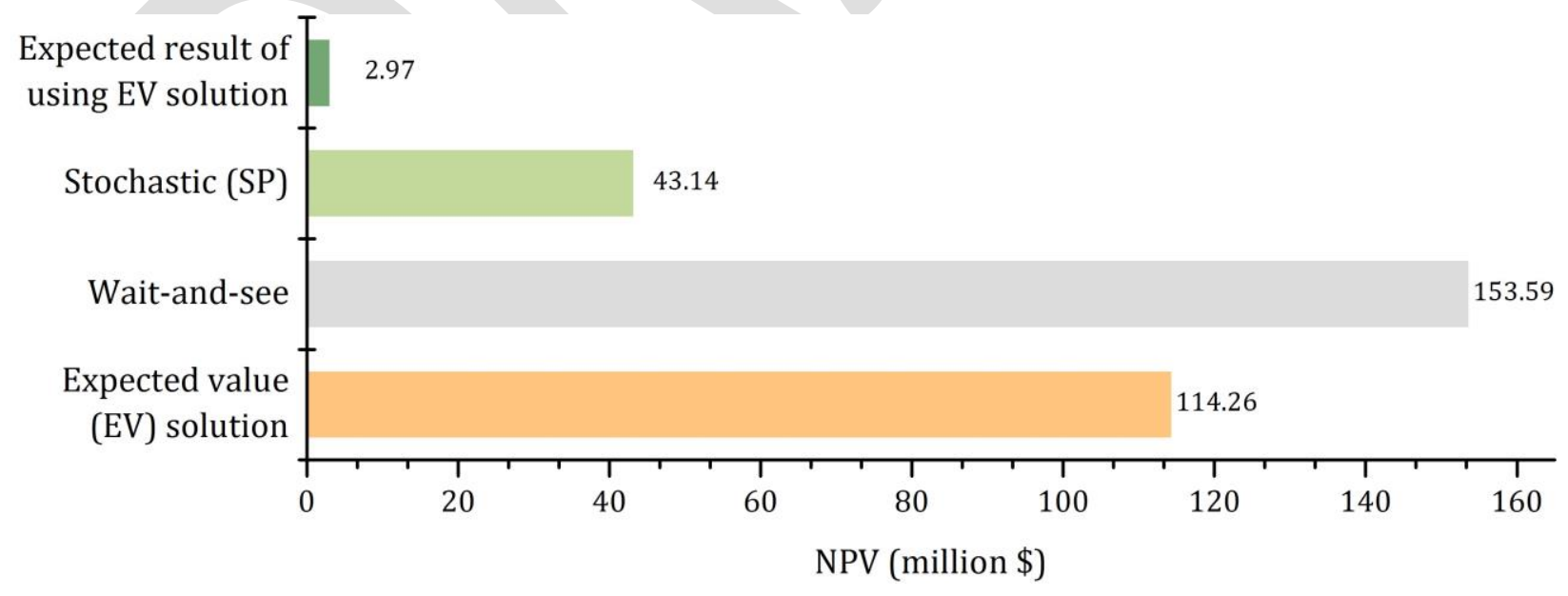

Figure 8. Optimal solutions for the 6 well-pad case study. 

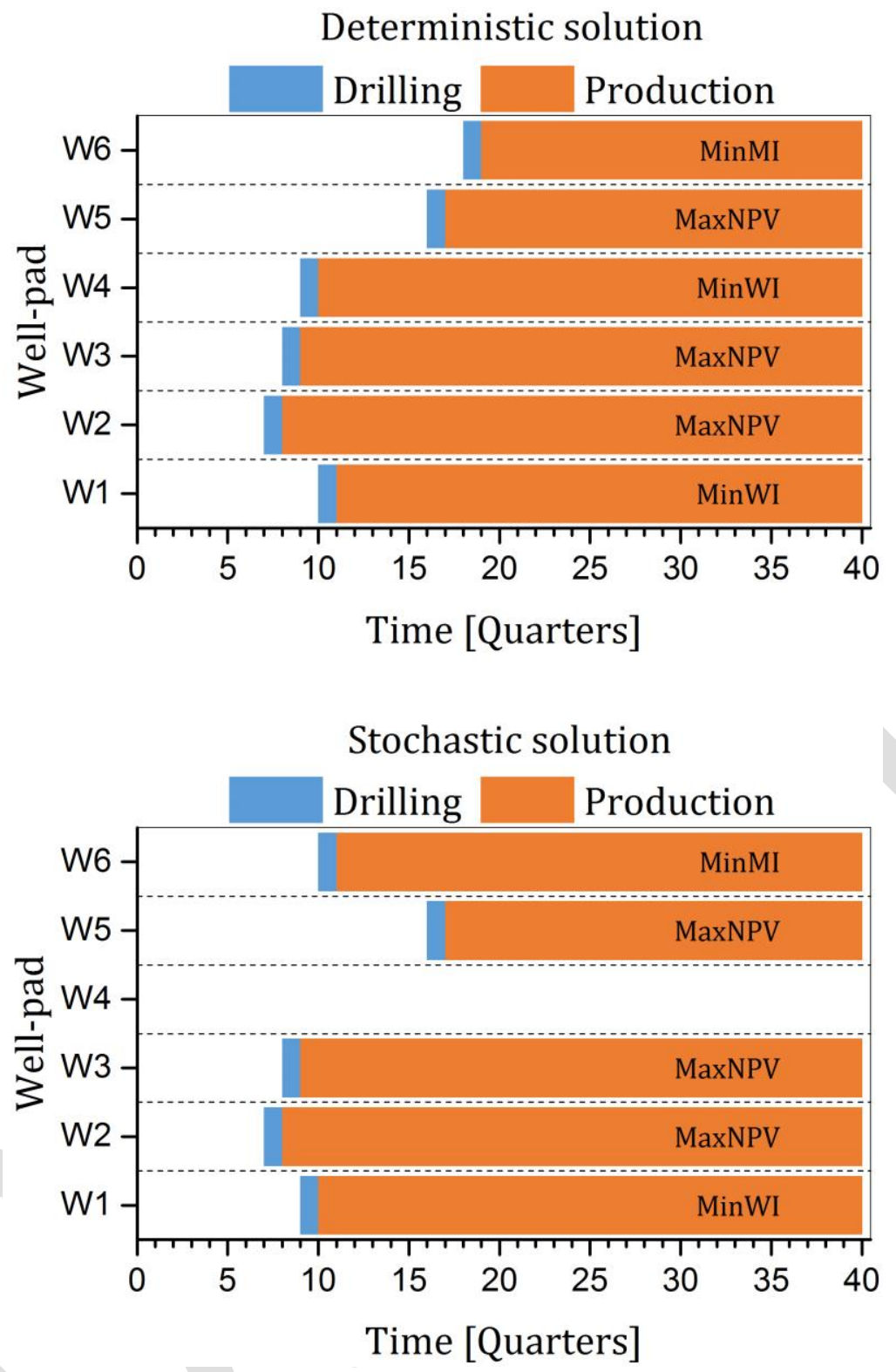

Figure 9. Deterministic versus stochastic solutions for the 6 well-pad case study. 


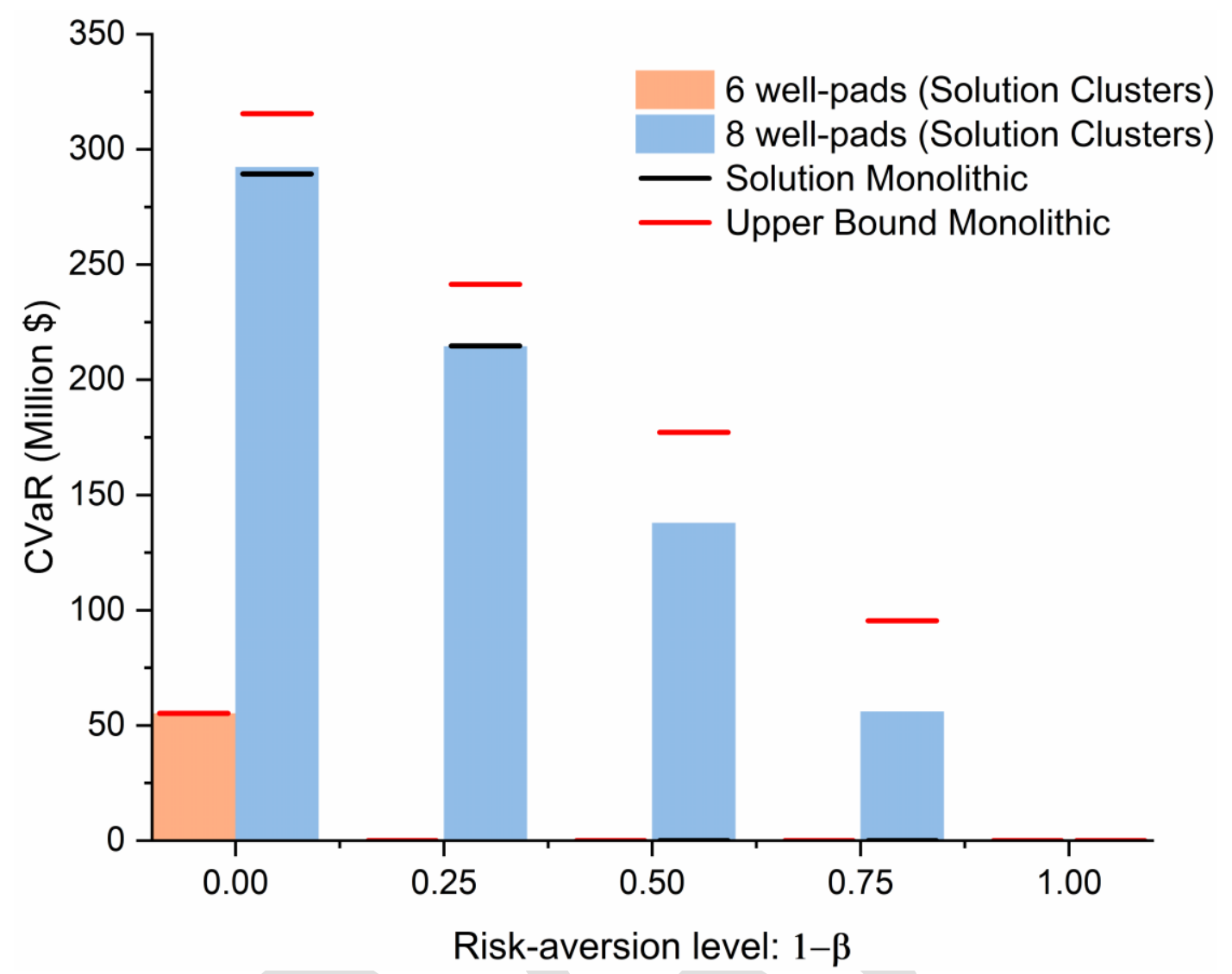

Figure 10. Effect of different risk aversion levels $(1-\boldsymbol{\beta})$ on the economics of shale gas development. Integer solution and upper bound for the monolithic solution approach are reported for 48 hours of CPU time. The CPU time for the cluster solution approach varies between 40.9 and 43.4 hours for the 8 well-pads case study, depending on the value of $\mathbf{1}$ $\beta$. 

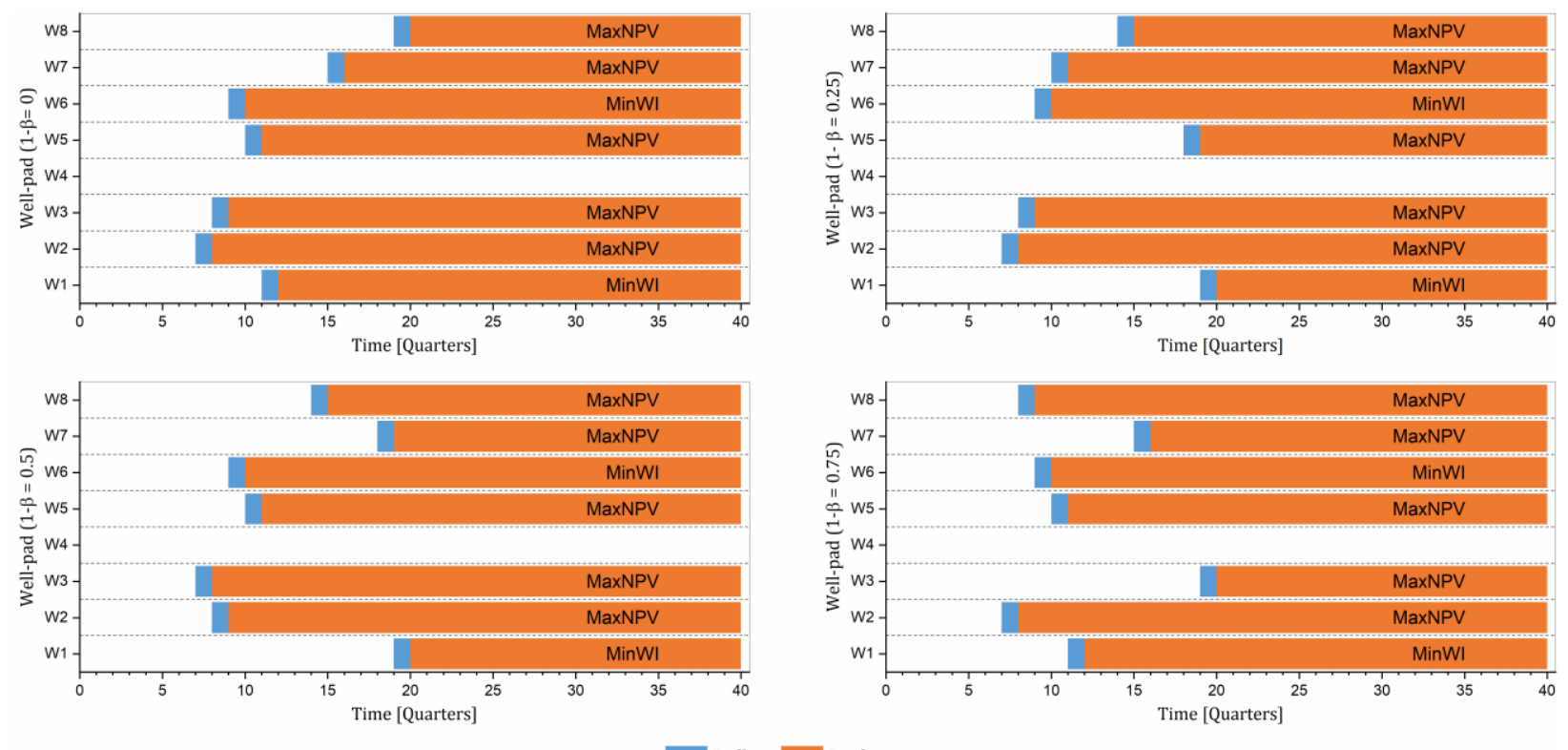

Drilling $\square$ Production

Figure 11. Optimal drilling strategy for case study with 8 well-pads and different levels of risk aversion $(1-\beta)$. 